\title{
Modular solid state behavioral training system
}

\author{
GARY R. SMITH* and SAMUEL L. WASSON \\ Lafayette Clinic, Michigan Department of Mental Health, 951 East Lafayette, Detroit, Michigan 48207
}

\begin{abstract}
A system of multifunction solid state modules to perform most behavioral training schedules is described. The system takes advantage of integrated circuit size, speed, reliability, economy, and sophistication to overcome the problems inherent in relay systems. However, unlike other approaches with solid state units, knowledge of circuit design is not required. The usual complexity of changing from one program to another is reduced to the simplicity of turning a switch.
\end{abstract}

The solid state system described in this paper overcomes many of the problems of relay control systems while integrating easily with electromechanical response and reinforcement devices. The system consists of four modules: a PROGRAM module, a CLOCK module and an IRT/HIST module, with an approximate parts cost of $\$ 100$ and a module supply with a parts cost of approximately $\$ 40$.

\section{THE SYSTEM}

The PROGRAM module is designed to connect directly to a response switch for input and most reinforcement devices for output (e.g., LVE 114-02 dipper, 114-20 feeder, etc.). The unit shown in Fig. 1 allows $E$ to manipulate five schedules of reinforcement: fixed ratio (FR), fixed interval (FI), Sidman avoidance (SA), differential reinforcement for low rates (DRL), and differential reinforcement for high rates (DRH). For FR, the investigator sets the rotary switch, SWP, to the FR position and selects the number of responses required for reinforcement on the two thumbwheel switches, SW 1 and SW 10. Example: for FR 25, SWP is set to FR, SW 1 to 5 , and SW 10 to 2. The response lever and the reinforcement device are connected to their corresponding snap studs on the module. The response lever, when pressed, triggers a one shot (74121), and its output is counted by the internal counters $(74901$ and 10). The outputs of these counters are compared to the settings on Switches SW 1 and SW 10 (in the 7485s); when the numbers match, an output is applied to a one shot through a gate. The duration of this one-shot output (reinforcement time) is variable from $350 \mathrm{msec}$ to $2.5 \mathrm{sec}$ and is determined by the setting of RT. The one-shot output drives a transistor connected to the reinforcement and is also used to reset the counters, thus restarting the cycle.

For the FI schedule, SWP is set to FI and an appropriate timing signal is connected to the CLOCK input. All other connections are the same as for FR. If a 1-pulse/sec rate is applied to the CLOCK input, the

\footnotetext{
*R equests for reprints should be forwarded to Gary Smith, Electronics Laboratory, Lafayette Clinic, 951 East Lafayette, Detroit, Michigan 48207.
}

counter output will represent time in seconds. The counter output is again compared to the settings on SW 1 and SW 10. When the desired number is reached, the next response triggers the one shot and turns on the reinforcement transistor. The one-shot out put also resets the counters so that the next interval can begin.

For Sidman avoidance conditioning, SWP is set to SA and an additional timing signal is connected to the SA CLOCK input. All other connections are the same as for FI. The counters still represent the number of timing pulses applied to the CLOCK input. The setting on the thumbwheel switches, SW 1 and SW 10, is the interval of time (RS) during which no reinforcement will occur. A response will initiate or reinitiate this interval at any time. The termination of the RS interval initiates a periodic reinforcement--usually an aversive stimulus. The stimulus duration (AS) will be the "on" duration of the one shot, which is again determined by the setting of RT. The interval from the beginning of one stimulus to the next, AS, plus the interstimulus interval, SS, is the time between timing pulses applied to the SA CLOCK input $(\mathrm{AS}+\mathrm{SS}=\mathrm{SA}$ CLOCK time $)$. The aversive stimulus interval continues until a response is made, which reinitiates the RS interval.

DRL has all of the connections used for FI. The only difference between the circuit function for FI and DRL is that the response is used to reset the counters in this schedule. This means that the selected period of time set on SW 1 and SW 10 must elapse between responses in order for a reinforcement to be delivered. The first response after the time has elapsed triggers the output one shot, delivers a reinforcement, and starts the next interval.

For DRH, the connections are the same as for FR except for the addition of a timing signal to the CLOCK input. The module functions the same as for FR, with the counters counting responses and SW 1 and SW 10 set for the number of responses required for reinforcement. The timing signal, however, is used to reset the counters, which requires that the specified number of responses must occur between two clock pulses in order to produce a reinforcement. Even if the required number of responses occur at the desired rate, a reinforcement may not result if the response train overlaps a clock pulse. 


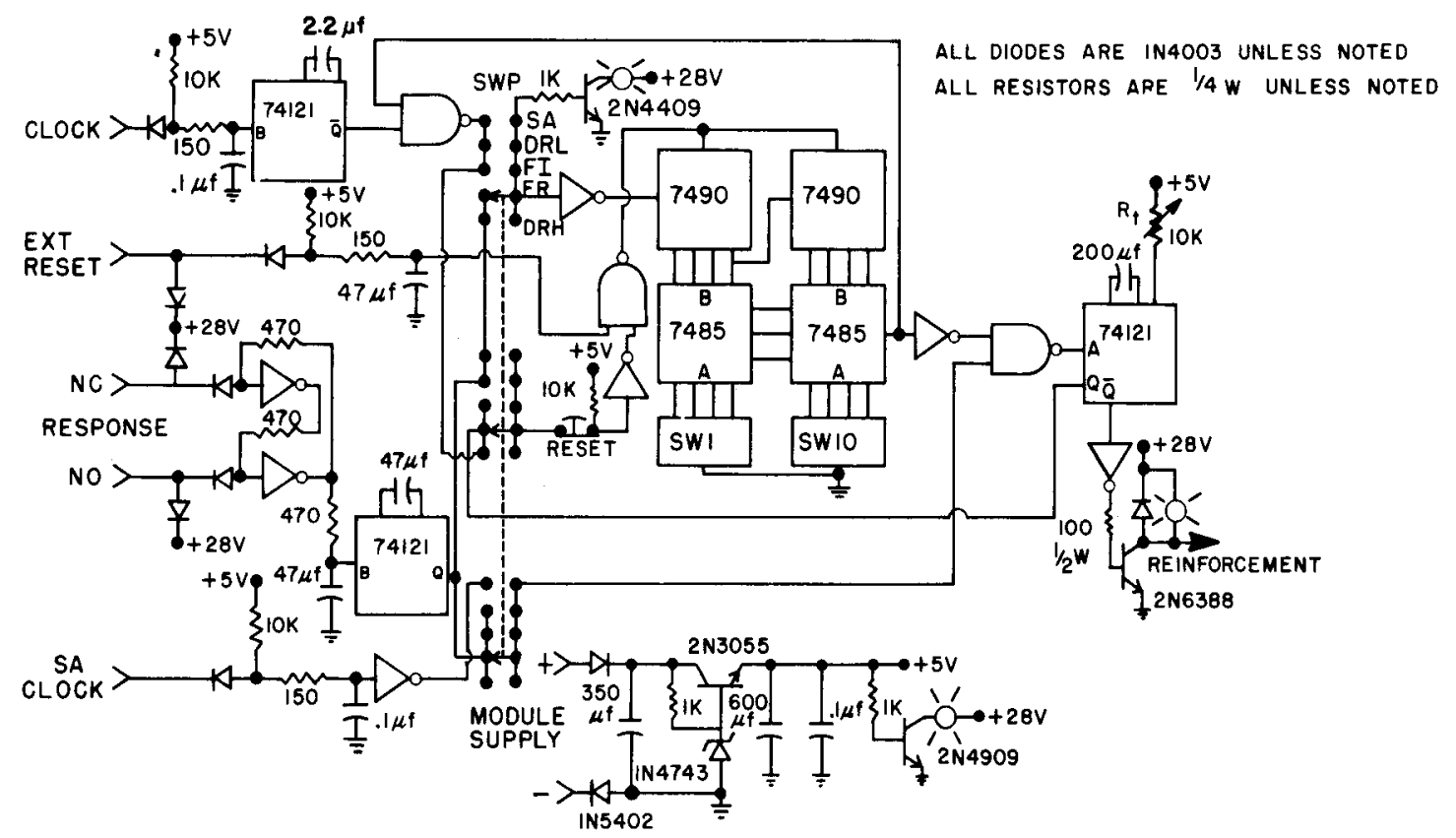

Fig. 1. The PROGRAM module produces any one of five reinforcement schedules, selectable by Switch SWP.

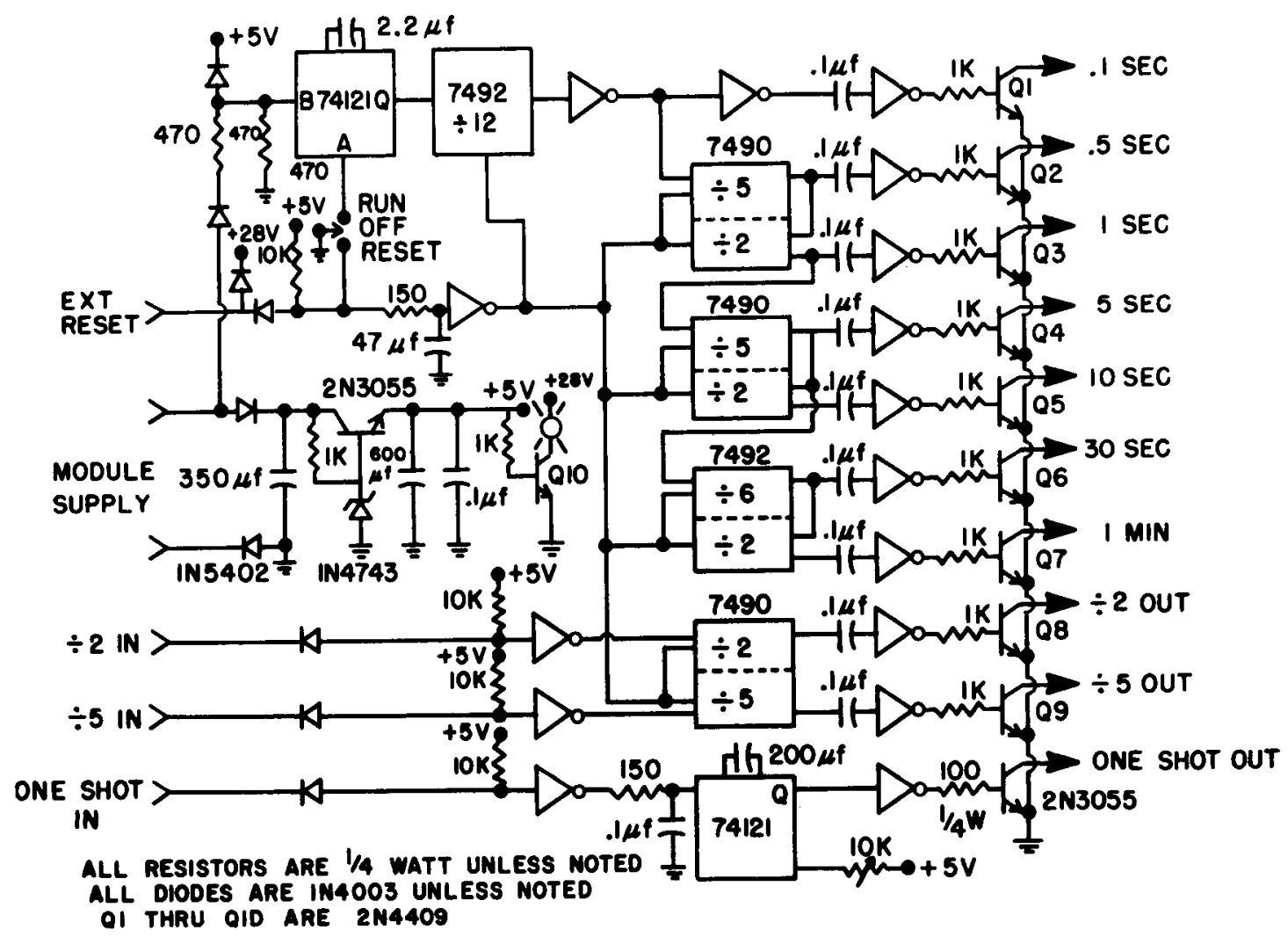

Fig. 2. The CLOCK module provides seven simultaneous output timing rates, a divide by two, a divide by five, and a one-shot driver. 
ALL DIODES ARE IN4003 UNLESS NOTED ALL RESISTORS ARE $1 / 4 W$ UNLESS NOTED

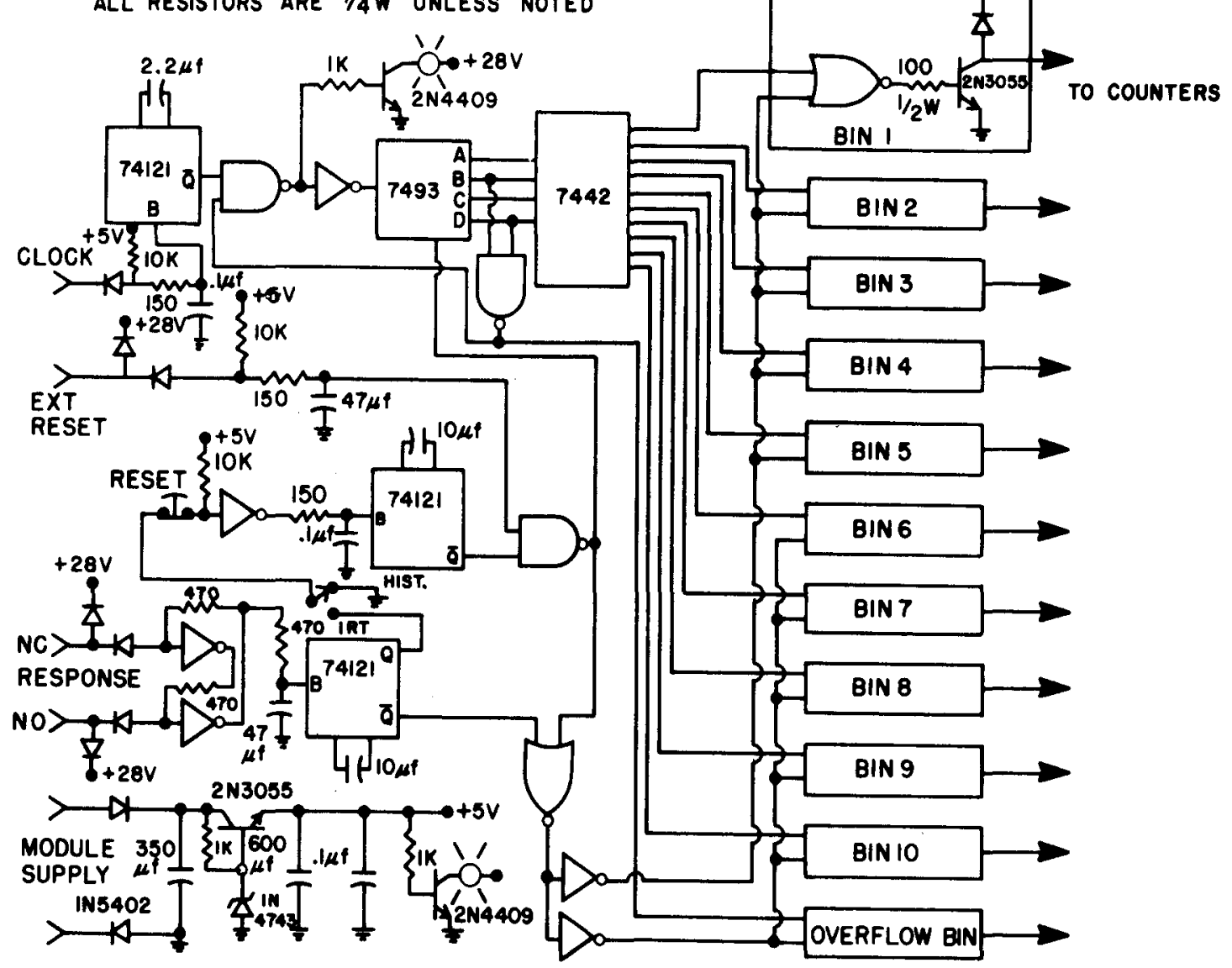

Fig. 3. The IRT/HIST module sorts responses into 10 bins in an interresponse time distribution or a postreinforcement histogram distribution.

VR and VI schedules can also be implemented easily with the use of a tape programmer. For VR, the tape programmer switch contacts can be connected to the module response input and the module set to FR-1. Caution should be taken to ensure that the module is the only connection to the switch. If any $28-\mathrm{V}$ devices are across these connections, damage may result in the module because there is no internal diode to clamp the large transients created by the collapsing field of a relay or solenoid.

The portion of the circuit that connects to the module supply is the voltage regulator for the integrated circuits. This is a standard transistor and Zener regulator with a 5-V output. This regulation is required to insure stable operation of the circuit.

The CLOCK module, as shown in Fig. 2, is designed to provide seven simultaneous pulse-output intervals: $0.1,0.5,1,5,10,30$, and $60 \mathrm{sec}$. These intervals were chosen to fit our research requirements; if shorter or longer intervals are preferred, only slight modification is necessary. All of the timing intervals are a division of the $120 \mathrm{~Hz}$ (full wave rectified $60 \mathrm{~Hz}$ ) supplied by the module supply, which affords high accuracy at low cost. The $120 \mathrm{~Hz}$ is first divided by 12 to produce the $10 \mathrm{~Hz}$ for the $0.1-\mathrm{sec}$ interval. This output is then applied to a series of dividers which further reduces the frequency to provide the longer intervals. If even slower rates are desired, additional dividers will provide them. A reset switch is included to allow for resetting the dividers. Once the dividers are reset, all of the timing outputs are synchronized to the fastest rate, and to each other. Two additional dividers are in the module to increase the existing intervals by factors of two and five, thus providing additional timing intervals (e.g., a $0.5-\mathrm{sec}$ interval divided by 5 will yield a 2.5 -sec interval). A one-shot driver is also added so that any timing signal can operate electromechanical devices directly. The regulator in the circuit performs the same function as it does in the PROGRAM module.

The two methods of measuring response rate in our experiments were interresponse time (IRT) and postreinforcement histogram (HIST). Figure 3 is the circuit diagram for the IRT/HIST module that performs these functions. When switched to IRT, the time 


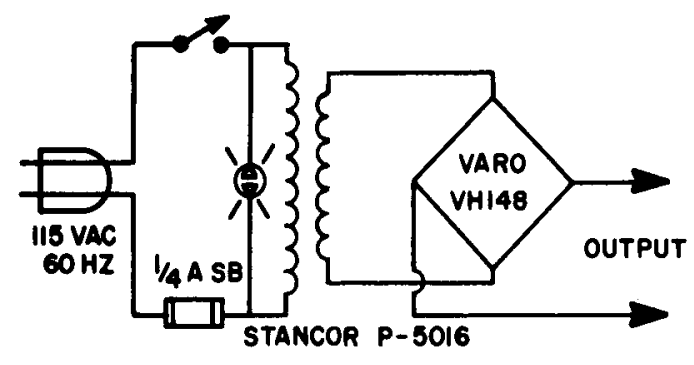

Fig. 4. The module supply provides both the power to each module and the time base for the CLOCK module.

between responses is sorted into 10 time bins and an overflow bin. In this mode, the response lever is connected to the module, and each press of the lever triggers a one shot, the duration of which is fixed but should be set to provide enough time to operate an electromechanical counter. The only other input is a timing signal. This signal determines the duration of each counter bin (e.g., a 1-pulse/sec rate will produce l-sec time bins). The circuit routes each input response through a series of gates to the appropriate bin for counting. After being counted, the circuit is reset and begins stepping through the bins from 1 to 10 or until the next response. If no response occurs prior to the end of the 10th bin, the circuit goes into an overflow condition and stops. When the next response is made, it is counted in the overflow bin, the circuit resets, and the process of stepping through the bins begins again. In the HIST mode, the only difference is in the resetting of the cycle; the circuit is reset with each reinforcement. If no reinforcement occurs before the end of the 10 th bin, the circuit again goes into the overflow state and all following responses are counted in the overflow bin until a reinforcement is given. With each reinforcement, the cycle is reinitiated. This reset function is accomplished by connecting the external reset input to the reinforcement driver. The voltage regulator performs the same function as in the other modules.

The module supply shown in Fig. 4 provides power to each of the function modules and each module has its own voltage regulator. We found this arrangement more reliable than using a single regulated supply for the entire system. The module supply need contain only a transformer and rectifier. The transformer drops the $120 \mathrm{~V}$ down to $10 \mathrm{~V}$, with 4-A capability. When rectified, this produces $14 \mathrm{~V}$, which is sufficient for good regulation. The rectifier is a full wave bridge with 6-A capability. This combination allows up to 12 function modules to be driven by one module supply.

Figure 5 shows the PROGRAM module, as constructed for our use. With the size and performance abilities of TTL integrated circuits and printed circuit board construction, we were able to mount the modules on the standard power rods formerly used for electromechanical devices. To simplify use, the front panel connections and controls were limited to those shown. Because the modules were designed to interface directly with standard response and reinforcement devices, snap studs were used for these input and output connections. Also, existing $28-\mathrm{V}$ supplies could be used for the remaining electromechanical units and the modules themselves.

These modules have been in use for several months with no failures.

\section{INTERFACE PROTECTION}

The system uses TTL 1 integrated circuits to provide the necessary counting, timing, and gating functions. There is, however, additional circuitry to provide the high degree of noise immunity required when connecting high-speed logic circuits to relays and solenoids. The noise-suppression circuits are incorporated into each of the modules, but only Fig. 1 will be referred to for the following explanations of them.

In order to prevent the logic-switching transients

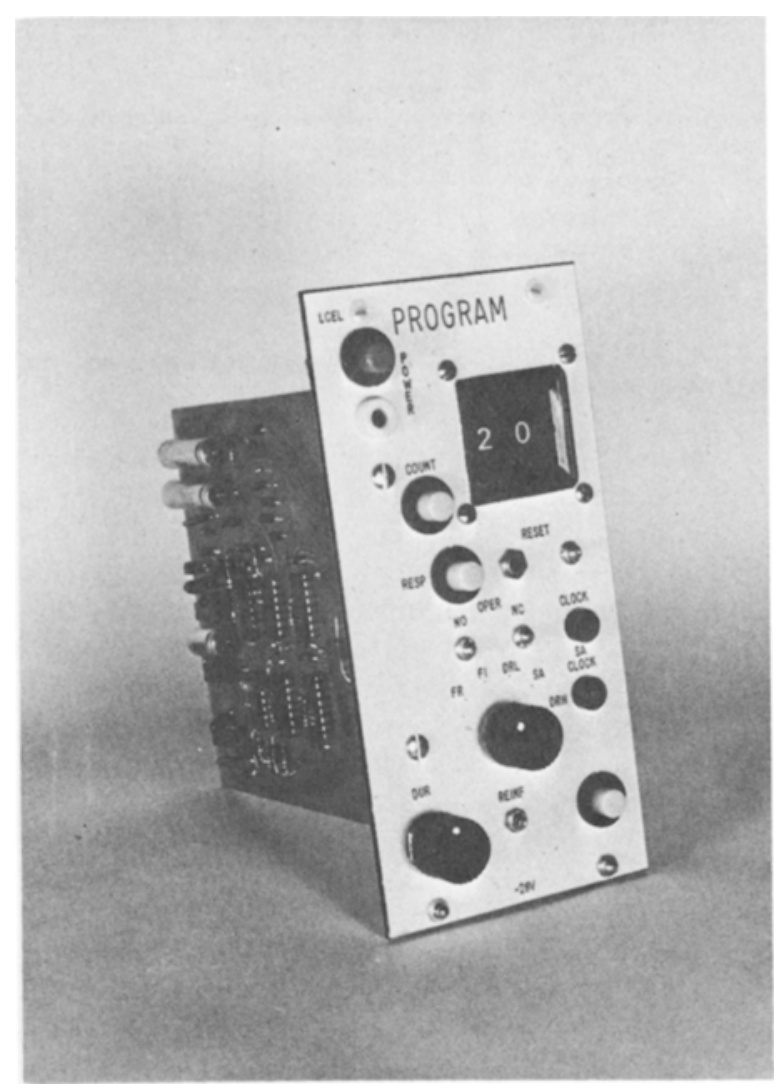

Fig. 5. Each of the modules, when completed, had front panel dimensions of $3^{1 / 2} \times 7$ in., allowing them to clip to the standard 28-V power rods. Snap studs were used for the connections to the response and reinforcement devices. 
one module from affecting those of another, each module has its own voltage regulator. In addition, each regulator is connected to the module supply through diodes. The diode at the positive input is to isolate the regulators from each other and to protect them from any reverse polarity potentials. The negative connection from the module supply is through the $28-\mathrm{V}$ power rod of the rack. The diode at this input to the module is to protect each module from transients created by the electromechanical devices in the system. The electrolytic capacitors remove any ripple; the $.1-$ microF capacitor is to compensate for the slow speed of the electrolytic.

The RESPONSE input circuit consists of two inverters connected as an R-S flip-flop and a one shot. The self-latching action of the R-S flip-flop eliminates "switch bounce" but, as a precaution, its output is applied to the Schmitt trigger input of the one shot through a low-pass filter. The one shot produces an output pulse of sufficient duration to operate the circuit logic. The diodes at the input of the R-S flip-flop protect the logic circuit when the switch is also connected to relay devices such as a cumulative recorder. One diode at each input is connected from the input to the $28 \mathrm{~V}$ in order to clamp the large transients caused by field collapse. The other diode prevents the $28 \mathrm{~V}$ from entering the logic circuit.

Table 1

Parts List: PROGRAM Module

\begin{tabular}{|c|c|c|c|}
\hline Quantity & Description & & Number \\
\hline 1 & TTL IC NAND & & SN7400 \\
\hline 1 & TTL IC HEX INV & & SN7404 \\
\hline 2 & TTL IC 4-bit MAG COMP & & SN7485 \\
\hline 2 & TTL IC BCD decade counter & & SN7490 \\
\hline 3 & TTL IC one shot & & SN74121 \\
\hline 3 & Transistors & Motorola & MPS3705 \\
\hline 1 & Transistor & Motorola & $2 \mathrm{~N} 3055$ \\
\hline 1 & Transistor & $\mathrm{RCA}$ & 2N6388 \\
\hline 10 & Diode & Motorola & $1 \mathrm{~N} 4003$ \\
\hline 1 & Diode & Westinghouse & $1 \mathrm{~N} 5402$ \\
\hline 1 & Diode & International Rect. & 1N4734 \\
\hline 1 & Resistor $-100 \mathrm{ohm}, 1 / 2 \mathrm{~W}$ & & \\
\hline 3 & Resistor $-150 \mathrm{ohm}, 1 / 4 \mathrm{~W}$ & & \\
\hline 3 & Resistor $-470 \mathrm{ohm}, 1 / 4 \mathrm{~W}$ & & \\
\hline 4 & Resistor- $1 \mathrm{~K}$ ohm, $1 / 4 \mathrm{~W}$ & & \\
\hline 12 & Resistor $-10 \mathrm{~K}$ ohm, $1 / 4 \mathrm{~W}$ & & \\
\hline 1 & Potentiometer-10K & Mallory & $\mathrm{U} 20$ \\
\hline 3 & Capacitor-.1 microfarad & Sprague & HY -360 \\
\hline 4 & Capacitor -47 microfarad & Sprague & $196 \mathrm{D} 476 \times 9006 \mathrm{KAl}$ \\
\hline 1 & Capacitor -350 microfarad & Sprague & TE1 166 \\
\hline 1 & Capacitor -200 microfarad & Sprague & TE1104 \\
\hline 1 & Capacitor-600 microfarad & Sprague & TE1108.5 \\
\hline 2 & Switch-BCD compliment & Imlec & $1 \mathrm{RBC} 10 \mathrm{~N} 1248$ \\
\hline 1 & Switch- 4 pole, 5 position rotary & Oak & $399-329 \mathrm{~F}$ \\
\hline 1 & Switch-SPST pushbutton & Alco & MPS-103B \\
\hline 1 & Switch hardware set & Imlec & $1 \mathrm{H}-2$ \\
\hline 1 & Switch end plate set & Imlec & IREP \\
\hline 1 & Connector-PC board, TWR cinch & & $50-30 A-30$ \\
\hline 2 & Tip jacks & E. F. Johnson & $105-0803-001$ \\
\hline 1 & Banana jack & E. F. Johnson & $108-0907-001$ \\
\hline 4 & Lamp sockets & GTE Sylvania & $30154-0$ \\
\hline 4 & Lamps & GTE Sylvania & 28PSB \\
\hline 3 & Lens caps & GTE Sylvania & $38002-0$ \\
\hline 1 & Lens cap & GTE Sylvania & $38001-0$ \\
\hline 2 & Knobs & Ray theon & $70-1-1$ \\
\hline 6 & Snap studs & Allied & $873-0813$ \\
\hline 4 & Fuse clips & Little Fuse & 101002 \\
\hline 2 & Threaded stand offs & H. H. Smith & 8342 \\
\hline 3 & Solder lugs & Allied & $1412-6$ \\
\hline 4 & Screws-No. $4,40 \times 3 / 4$ in. & & \\
\hline 4 & Screws-No. $6,32 \times 1 / 2$ in. & & \\
\hline 2 & Screws nylon-No. $6,32 \times 1 / 4$ in. & Allied & 2503 \\
\hline 6 & Lock washers - No. 6 & & \\
\hline 2 & Nuts No. $6,32 \times 1 / 4$ in. & & \\
\hline 1 & Printed circuit board & \multirow{2}{*}{\multicolumn{2}{|c|}{ Made at our facility }} \\
\hline 1 & Front panel & & \\
\hline
\end{tabular}


Table 2

Parts List: CLOCK Module

\begin{tabular}{|c|c|c|c|}
\hline Quantity & Description & & Number \\
\hline 3 & TTL IC HEX INV & & SN7404 \\
\hline 3 & TTL IC BCD decade counter & & SN7490 \\
\hline 2 & TTL IC divide by 12 & & SN7492 \\
\hline 2 & TTL IC one shot & & SN74121 \\
\hline 10 & Transistors & Motorola & MPS 3705 \\
\hline 2 & Transistors & Motorola & $2 N 3055$ \\
\hline 9 & Diodes & Motorola & $1 \mathrm{~N} 4003$ \\
\hline 1 & Diode & Westinghouse & $1 \mathrm{~N} 5402$ \\
\hline 1 & Diode & International Rect. & $1 \mathrm{~N} 4734$ \\
\hline 1 & Resistor-100 ohm, $1 / 2 \mathrm{~W}$ & & \\
\hline 2 & Resistors $-150 \mathrm{ohm}, 1 / 4 \mathrm{~W}$ & & \\
\hline 2 & Resistors $-470 \mathrm{ohm}, 1 / 4 \mathrm{~W}$ & & \\
\hline 11 & Resistors-1K ohm, $1 / 4 \mathrm{~W}$ & & \\
\hline 4 & Resistors $-10 \mathrm{~K}$ ohm, $1 / 4 \mathrm{~W}$ & & \\
\hline 1 & Potentiometer $-10 \mathrm{~K}$ ohm & Mallory & $\mathrm{U} 20$ \\
\hline 11 & Capacitors-- 1 microfarad & Sprague & HY -360 \\
\hline 1 & Capacitors -2.2 microfarad & Sprague & $225 \times 9025 \mathrm{HA} 1$ \\
\hline 1 & Capacitors -47 microfarad & Sprague & $196 \mathrm{D} 476 \mathrm{X} 9006 \mathrm{KA} 1$ \\
\hline 1 & Capacitors -200 microfarad & Sprague & TE1 104 \\
\hline 1 & Capacitors-350 microfarad & Sprague & TE1166 \\
\hline 1 & Capacitors -600 microfarad & Sprague & TE 1108.5 \\
\hline 1 & Switch-SPDT on-off-mom. & Alco & MST- $105 \mathrm{H}$ \\
\hline 1 & Connector-PC board, TWR cinch & & $50-30 A-30$ \\
\hline 3 & Tip jack & E. F. Johnșon & $105-0803-001$ \\
\hline 33 & Tip jacks & E. F. Johnson & $105-0801-001$ \\
\hline 1 & Banana jack & E. F. Johnson & $108-0907-001$ \\
\hline 2 & Lamp sockets & GTE Sylvania & $30154-0$ \\
\hline 2 & Lamps & GTE Sylvania & 28PSB \\
\hline 1 & Lens cap & GTE Sylvania & $38002-0$ \\
\hline 1 & Lens cap & GTE Sylvania & $38001-0$ \\
\hline 1 & Knob & Raytheon & $70-1-1$ \\
\hline 4 & Snap studs & Allied & $873-0813$ \\
\hline 4 & Fuse clips & Little Fuse & 101002 \\
\hline 2 & Threaded standoffs & H. H. Smith & 8342 \\
\hline 5 & Solder lugs & Allied & $1412-6$ \\
\hline 4 & Screws-No. $6,32 \times 1 / 2$ in. & & \\
\hline 2 & Screws nylon-No. $6,32 \times 1 / 4$ in. & Allied & 2503 \\
\hline 5 & Lockwashers -No. 6 & & \\
\hline 4 & Nuts-No. $6,32 \times 1 / 4$ in. & \multirow{3}{*}{ Made at our facility } & \\
\hline 1 & Printed circuit board & & \\
\hline 1 & Front panel & & \\
\hline
\end{tabular}

The EXT RESET input has the same diode input arrangement to serve the same function as the response input. A $10 \mathrm{~K}-\mathrm{ohm}$ resistor is used to provide bias for the logic, and a low-pass filter eliminates noise transients.

The CLOCK inputs use only one diode to protect the input from accidental connection to the $28 \mathrm{~V} \mathrm{~V}$ supply. These inputs are designed to be connected to the
CLOCK module and not to relays or solenoids. The low-pass filter performs the same function as in the other circuits.

Output protection is also necessary to prevent the output transistors from being damaged by the large voltage transients created by the reinforcement devices when turned off. The diode connected from the 
Table 3

Parts List: IRT/HIST Module

\begin{tabular}{|c|c|c|c|}
\hline Quantity & Description & & Number \\
\hline 1 & TTL IC NAND & & SN7400 \\
\hline 3 & TTL IC NOR & & SN7402 \\
\hline 1 & TTL IC HEX INV & & SN7404 \\
\hline 1 & TTL IC BCD to DEC decoder & & SN7442 \\
\hline 1 & TTL IC 4-bit binary counter & & SN7493 \\
\hline 3 & TTL IC one shot & & SN74121 \\
\hline 2 & Transistors & Motorola & MPS3705 \\
\hline 13 & Transistors & Motorola & $2 \mathrm{~N} 3055$ \\
\hline 20 & Diodes & Motorola & $1 \mathrm{~N} 4003$ \\
\hline 1 & Diode & Westinghouse & $1 \mathrm{~N} 5402$ \\
\hline 1 & Diode & International Rect. & $1 \mathrm{~N} 4734$ \\
\hline 12 & Resistors $-100 \mathrm{ohm}, 1 / 2 \mathrm{~W}$ & & \\
\hline 3 & Resistors $-150 \mathrm{ohm}, 1 / 4 \mathrm{~W}$ & & \\
\hline 3 & Resistors $-470 \mathrm{ohm}, 1 / 4 \mathrm{~W}$ & & \\
\hline 3 & Resistors-1K ohm, $1 / 4 \mathrm{~W}$ & & \\
\hline 3 & Resistors-10K ohm, $1 / 4 \mathrm{~W}$ & & \\
\hline 3 & Capacitors- .1 microfarad & Sprague & HY-360 \\
\hline 2 & Capacitors-10 microfarad & Sprague & TE 1087 \\
\hline 3 & Capacitors -47 microfarad & Sprague & $196 \mathrm{D} 476 \times 9006 \mathrm{KAl}$ \\
\hline 1 & Capacitor-350 microfarad & Sprague & TE 1166 \\
\hline$\hat{1}$ & Capacitor -600 microfarad & Sprague & TE1108.5 \\
\hline 1 & Switch-SPDT & Alco & MST105D \\
\hline 1 & Switch-SPST pushbutton & Alco & MSP-103B \\
\hline 1 & Connector-PC board, TWR cinch & & $50-30 A-30$ \\
\hline 1 & Tip jack & E. F. Johnson & $105-0803-001$ \\
\hline 1 & Banana jack & E. F. Johnson & $108-0907-001$ \\
\hline 3 & Lamp sockets & GTE Sylvania & $30154-0$ \\
\hline 3 & Lamps & GTE Sylvania & 28PSB \\
\hline 1 & Lens cap & GTE Sylvania & $38001-0$ \\
\hline 2 & Lens caps & GTE Sylvania & $38002-0$ \\
\hline 15 & Snap studs & Allied & $873-0813$ \\
\hline 4 & Fuse clips & Little Fuse & 101002 \\
\hline 2 & Threaded standoffs & H. H. Smith & 8342 \\
\hline 19 & Solder lugs & Allied & $1412-6$ \\
\hline 4 & Screws-No. $6,32 \times 3 / 2$ in. & & \\
\hline 2 & Screws nylon-No. $6,32 \times 1 / 4$ in. & Allied & 2503 \\
\hline 4 & Lockwashers-No. 6 & & \\
\hline 2 & Nuts-No. $6,32 \times 1 / 4$ in. & & \\
\hline 1 & Printed circuit board & & \\
\hline 1 & Front panel & Made at our facility & \\
\hline
\end{tabular}

Table 4

Parts List: Module Supply

\begin{tabular}{|c|c|c|c|}
\hline Quantity & Description & & Number \\
\hline 1 & Bridge rectifier & Varo & $\mathrm{VH} \cdot 148$ \\
\hline 1 & Fuse holder & Bussman & KHP \\
\hline 1 & Lamp & Lee Craft & $36 N 2311$ \\
\hline 1 & Switch-SPDT & Alco & MST-105D \\
\hline 1 & Power cord & Columbia & 24596 \\
\hline 8 & Fuse clips & Little Fuse & 101002 \\
\hline 4 & Banana jacks & E. F. Johnson & $108-0907-001$ \\
\hline 4 & Solder lugs & Allied & $1412-6$ \\
\hline 4 & Snap studs & Allied & $873-0812$ \\
\hline 1 & Screw-No. $6,32 \times 1 / 2$ & & \\
\hline 4 & Screw nylon-No. 6 & & \\
\hline & $32 \times 1 / 4$ in. & Allied & 2503 \\
\hline 4 & Screws-No. $8,32 \times 1 / 2$ & & \\
\hline 5 & Lockwashers-No. 6 & & \\
\hline 4 & Lockwashers-No. 8 & & \\
\hline 5 & Nuts-No. $6,32 \times 1 / 4$ in & & \\
\hline 4 & Nuts-No. $8,32 \times 3 / 8$ & & \\
\hline 1 & Transformer & Stancor & P-5016 \\
\hline 1 & Front panel & \multicolumn{2}{|c|}{ Made at our facility } \\
\hline
\end{tabular}

collector of the $2 \mathrm{~N} 6388$ transistor to the $28 \mathrm{~V}$ provides the necessary clamping action. The 2 N6388 is a monolithic Darlington with a $\mathrm{P}_{\mathrm{t}}=40 \mathrm{~W}$, an $\mathrm{h}_{\mathrm{fe}}=1,000$ (a) $5 \mathrm{~A}$, and an $\mathrm{I}_{\mathbf{c}}=15 \mathrm{~A} \max$. It was chosen to ensure that the necessary current-sinking requirement would be met for all reinforcement devices.

Parts lists for the modules (PROGRAM, CLOCK, IRT/HIST) and the module supply are provided in Tables 1-4, respectively.

\section{NOTE}

1. Texas Instruments, Inc., The Integrated Circuit Catalog for Design Engineers, First Edition, 1972. 